\title{
REFLECTION
}

\section{Lessons From My Left Foot}

\section{Thomas Bodenheimer, $M D$}

Department of Family and Community Medicine, University of California at San Francisco, San Francisco, California

Conflicts of interest: none reported

\section{CORRESPONDING AUTHOR}

Thomas Bodenheimer, MD Department of Family and Community Medicine

University of California at San Francisco Bldg 80-83, San Francisco General Hospital 995 Potrero Ave

San Francisco, CA 94110

TBodenheimer@fcm.ucsf.edu

\begin{abstract}
A personal experience with a chronic foot injury taught me 4 lessons about living with a chronic condition: people with chronic conditions may blame themselves, may feel guilty that other people have to help them, often have a depression that may be worse than the chronic condition, and may lose confidence in their capacity to do anything useful in life. These feelings need to be elicited and addressed when family physicians provide care to people with chronic conditions.
\end{abstract}

Ann Fam Med 2010;8:550-551. doi:10.1370/afm.1170.

A s a primary care physician, I have cared for patients with chronic illness for decades. I have studied chronic disease. I have tried to improve chronic disease care at several primary care clinics. But it's my left foot that really taught me about chronic disease.

My feet have carried me thousands of miles in my life-walking to work on those hard cement sidewalks, going over high mountain passes with heavy packs. For 25 years I played basketball every Saturday morning on a cement outdoor court, often in old worn-down shoes. Eight months ago, my left foot told me, "Enough abuse. I'm going on strike." Because of the pain, I could bear no weight. I contacted my primary care physician at once. Four medical consultations, 2 negative imaging studies, and innumerable care plans-immobilization, ice, anti-inflammatories, no weight bearing, taping, wrapping, elevating, and a slew of orthotics-I still could not bear weight on the painful left foot. Diagnosis: soft tissue injury of some sort. Treatment: see what helps and keep doing that. "Maybe you'll be better soon."

It felt chronic. Unable to walk for many weeks without crutches, my life had changed in every way. What did my left foot tell me about how people with chronic conditions feel? The foot taught me 4 lessons.

First, many people with chronic conditions blame themselves. In my case, it's justified ${ }_{i}$ I have abused my feet. I imagine that the person with diabetes who does not exercise, eats unhealthy foods, and is overweight may also feel a deep self-blame. It is not a helpful feeling even if true. Obsessing about the past and what I could have done to prevent it gets in the way of addressing the future. Perhaps we should be asking patients with chronic conditions whether they blame themselves and help them redirect their thoughts to more productive channels.

Second, I've been blessed with a partner who put her life on hold to take care of me. But I hate to have other people help me. It drags down my sense of self-worth to take and never give. I suspect that many people with functional limitations related to chronic conditions feel the same. Some, of course, have no one to help them. Those who do receive assistance may think themselves worthless, which does not contribute to a therapeutic state of mind.

The third message from my left foot is something that all experts in chronic disease emphasize: depression-the emotional consequence of not being able to do what one is used to. The depression may be worse than the disease. My foot hurts, but my mind hurts 10 times more. Because 
this depression is a result of the disease, treatment for the depression must include as its major focus a good plan for managing the disease. Also, the depression is variable. When my foot hurts more, my depression deepens. When my foot feels okay, my depression lifts. That is still true 8 months later. I remember Professor Kate Lorig, the chronic disease self-management scholar at Stanford, telling me why people with diabetes don't like to do home glucose testing: when they get a high glucose reading, they feel depressed. One sensible response: don't check your glucose levels. Mood can be so variable and so dependent on how a condition is behaving that day-elation with a normal glucose level or blood pressure, a few hours of relief from arthritis pain, some days of freedom from asthma attacks or congestive heart failure exacerbations.

What have I learned beyond what experts have written about chronic conditions and depression? That the depression can be the major aspect of the disease and can pull people down, down, down. That it waxes and wanes along with the disease. And that-adding together the passivity produced by self-blame, the disempowerment fed by needing help from other people, and the "I don't really care what happens" attitude from depression-people with chronic conditions must overcome major challenges to be active participants in their care.

The fourth lesson is about self-efficacy - the feeling of confidence that one can succeed and improve one's life. Self-efficacy is supposed to be activity specific. "I feel $100 \%$ sure that I can cook dinner tonight, but I have zero confidence that I can be the winning pitcher in the World Series." Yet an interesting thing happened to me when my left foot revolted and said, "No more walking." Naturally my confidence that I could get from one place to another plummeted. There was also a generalizing effect from that rational loss of confidence. I began to lose my confidence in everything. Can I still write? Can I complete the projects I am committed to doing? Am I a drag to be with? None of these things require my feet, but I began to lose all self-efficacy. The same might happen to others with chronic conditions-losing self-confidence not only for the activities truly limited by the chronic condition, but losing overall confidence in oneself as a human being.

If all these challenges I have experienced are similar to the burdens of the tens of millions of people with chronic conditions, then our obsessive focus on the glycated hemoglobin $\left(\mathrm{HbA}_{1 \mathrm{c}}\right)$ levels and peak flow readings may need rethinking. Certainly those outcomes are important, and the 4 interrelated psychosocial challenges should get better as the glucose levels and peak flow improve. Still, glucose levels and peak flow may not improve until those challenges are dis- cussed and addressed in patients' care plans. I used to think of quality of life or patient experience as secondclass measures, not reaching the level of importance held by "hard " clinical outcomes. I failed to consider that a $\mathrm{HbA}_{1 \mathrm{c}}$ level of $8.5 \%$ or a low-density cholesterol level of $138 \mathrm{mg} / \mathrm{dL}$ is asymptomatic. For many people, pain today trumps a stroke tomorrow. Feeling depressed today obliterates the importance of renal failure tomorrow. Clinical outcomes, such as overall quality of life, percentage of days with pain, or number of depression-free days, may be better patient-centered measures than laboratory numbers.

Eight months after the problem surfaced, I am better but not good. I can walk but not like before. The condition varies from hour to hour, day to day. It has become a chronic problem in partial remission. The anger, self-doubt, and emotional paralysis have gone away. Acceptance has set in. Most importantly, my problem is a musculoskeletal issue about a foot. Not progressive Alzheimer's, not the terrifying dyspnea of congestive heart failure or chronic pulmonary disease. What's the big deal?

Perhaps developing a condition that affected my most cherished activities made me react emotionally to a minor medical condition more than would others with serious disease. Perhaps I'm not as tough as other people. Not everyone with chronic disease becomes depressed and loses self-esteem. I suspect, however, that some of these feelings affect the patients we physicians see but are hidden behind the objective findings that command our attention. In the 15 -minute visit, addressing emotions and quality of life simply takes too long.

Did the health care system help me get better? As a physician, I got special treatment. What mattered the most was trust. Since I had no definitive diagnosis, I needed to trust the practitioners trying to help me. Having a trusted family physician and gaining trust in one specialist helped a great deal, even if the only effective treatment turned out to be tincture of time. For the loss of confidence and self-pity, help came from outside the health system: my partner, my coworkers, my friends. Perhaps those of us who provide health care overestimate our own importance and underestimate the critical role of social support-especially when it's lacking.

I'm really mad at my left foot. But I must admit, it has taught me a great deal.

To read or post commentaries in response to this article, see it online at http://www.annfammed.org/cgi/content/full/8/6/550.

Key word: Chronic care

Submitted January 14, 2010; submitted, revised, April 10, 2010; accepted April 27, 2010. 